\title{
Stroke Patients with Sinus Rhythm and Atrial Fibrillation: Comparison of Echocardiography Findings
}

\author{
(1) Abdullah Algın¹, (1) Mehmet Özgür Erdoğan², (1) Șahin Çolak², (1) Irrfan Aydın¹, (1) İsmail Tayfur², (1) Mustafa Ahmet Afacan², \\ (1) Hakan Aydın 3
}

1Department of Emergency Medicine, Adıyaman University Training and Research Hospital, Adıyaman, Turkey 2Department of Emergency Medicine, Haydarpașa Numune Training and Research Hospital, İstanbul, Turkey ${ }^{3}$ Department of Internal Medicine, Adıyaman University Training and Research Hospital, Adıyaman, Turkey

\begin{abstract}
Aim: To compare the echocardiographic findings in stroke patients with sinus rhythm and atrial fibrillation (AF).

Materials and Methods: Descriptive, cross-sectional study. Place and Duration of Study: Department of Emergency Medicine, Adıyaman University Education and Research Hospital, from January 2014 to December 2016. Four hundred and sixty-seven subsequent stroke patients were admitted to the study. Data included demographic and echocardiographic findings. Patients are divided into the AF and sinus rhythm groups. Categorical variables were analyzed with the Fischer's Exact Test and parametric variables with the Independent Samples T Test.

Results: AF patients with stroke had a significantly lower ejection fraction, decreased left ventricular function, increased left ventricular diameters, systolic dysfunction, mitral valve insufficiency, and tricuspid valve insufficiency.

Conclusion: AF patients with stroke had a significantly lower ejection fraction, decreased left ventricular function, increased left ventricular diameters, systolic dysfunction, mitral valve insufficiency, and tricuspid valve insufficiency. AF should not be considered as a major cardiac risk factor for stroke. AF may be a consequence of multifactorial cardiac abnormalities that may have a causative effect for stroke.
\end{abstract}

Keywords: Stroke, atrial fibrillation, echocardiography

\section{Introduction}

Atrial fibrillation (AF) is a common type of arrhythmia. It is a major risk factor for ischemic stroke, especially in the elderly (14). Its prevalence is $1 \%$ in population, and it increases up to $6 \%$ in people older than 65 years of age. Patients with non-valvular AF have higher risk of stroke $(1,2,4,5)$.

The aim of the study is to highlight the anatomical disorders accompanying AF in stroke patients. We evaluated the differences of echocardiographic findings in stroke patients with and without AF.

\section{Materials and Methods}

Stroke patients admitted to the emergency department of Adıyaman University Hospital between 2014 and 2016 were analyzed retrospectively. Stroke patients were identified with the ICD code I1.68 and AF patients were identified with the ICD code 148. All subsequent stroke patients' data were recorded to standard 
forms. Data included demographic and echocardiographic findings. Patients were divided into the AF and sinus rhythm groups. 467 patients were included in the study. Hundred and ten patients with recurrent stroke, hemorrhagic stroke, transient ischemic attacks and patients under 18 years of age and with incomplete data were excluded from the study. Patients were divided into the sinus rhythm and AF groups.

Table 1. Initial symptoms of patients in the emergency department

\begin{tabular}{ll}
\hline Symptoms & $\mathbf{n}(\%)$ \\
\hline Loss of consciousness & $92(19.70)$ \\
\hline Headache & $37(7.92)$ \\
\hline Hemiplegia, Hemiparesis & $313(67.02)$ \\
\hline Convulsion & $5(1.07)$ \\
\hline Dysarthria & $117(25.05)$ \\
\hline Vertigo & $49(10.49)$ \\
\hline General impairment & $40(8.56)$ \\
\hline
\end{tabular}

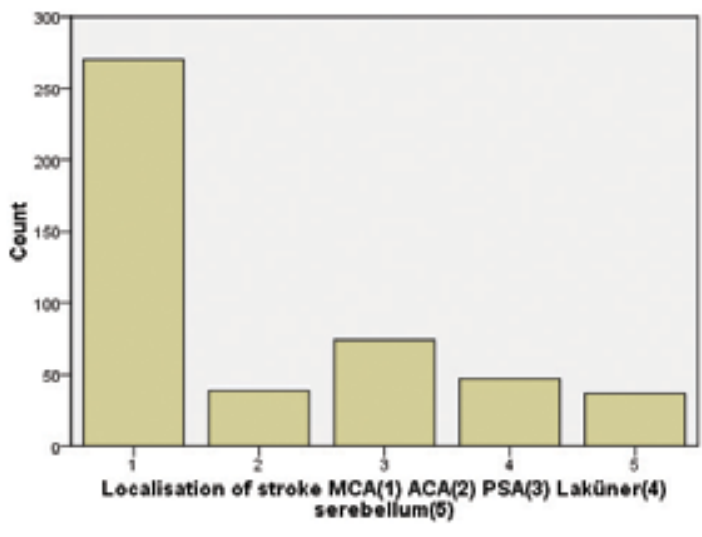

Figure 1. Localization of stroke. Middle cerebral artery (1), anterior cerebral artery (2), posterior cerebral artery (3), lacunar infarct (4), cerebellum (5)
This retrospective observational study was approved by the institutional local ethics committee of Adıyaman University Hospital (2017/5-10).

\section{Statistical Analysis}

Data were analyzed using the Statistical Package for Social Sciences (SPSS) ver. 20. Categorical variables were analyzed with the Fischer's Exact Test and parametric variables with the Independent Samples T Test. Binary logistic regression was used to calculate odds ratio and 95\% confidence interval.

\section{Results}

There were 237 (50.7\%) males and 230 (49.3\%) females. The mean age was $71.71 \pm 12.44$ years. The mean age of patients with AF was $77.76 \pm 8.43$ years and the mean age of patients with sinus rhythm was $70.53 \pm 12.75$ years $(p<0.05)$. Symptoms at admission are shown in Table 1.

Stroke localizations of all patients are shown in Table 2 and Figure 1. AF was noted on the initial electrocardiograms of 76 (16.2\%) patients.

The mean ejection fraction of patients was $51.07 \pm 10.41$ in the AF group and $55.54 \pm 9$ in the sinus rhythm group. Echocardiographic findings of all patients are shown in Table 3.

Table 2. Localization of stroke

\begin{tabular}{ll}
\hline & $\mathbf{n}(\%)$ \\
\hline Middle cerebral artery & $270(53.9)$ \\
\hline Anterior cerebral artery & $39(7.8)$ \\
\hline Posterior cerebral artery & $74(14.8)$ \\
\hline Lacunar infarction & $47(9.4)$ \\
\hline Cerebellum & $37(7.4)$ \\
\hline Total & 467 \\
\hline
\end{tabular}

Table 3. Echocardiographic findings

\begin{tabular}{|c|c|c|c|c|c|}
\hline & Sinus rhythm & Atrial fibrillation & $p$ value & Odds ratio & $95 \% \mathrm{Cl}$ \\
\hline Decreased left ventricular function & 46 & 24 & 0.00006 & 0.642 & $0.274-1.504$ \\
\hline Increased left ventricular diameters & 83 & 28 & 0.005 & 0.882 & $0.452-1.720$ \\
\hline Systolic dysfunction & 30 & 10 & 0.001 & 0.615 & $0.270-1.403$ \\
\hline Mitral valve insufficiency & 77 & 32 & 0.000085 & 0.723 & $0.360-1.453$ \\
\hline Tricuspid valve insufficiency & 25 & 20 & 0.000002 & 0.261 & $0.113-0603$ \\
\hline Diastolic dysfunction & 64 & 9 & 0.390 & - & - \\
\hline Intracardiac thrombus & 15 & 2 & $>0.05$ & - & - \\
\hline Increased atrial diameters & 46 & 11 & 0.565 & - & - \\
\hline Total & 391 & 76 & - & - & - \\
\hline $\mathrm{Cl}$ : Confidence interval & & & & & \\
\hline
\end{tabular}




\section{Discussion}

AF is a common arrhythmia associated with increased risk of stroke, heart failure and death. AF occurs in 1-2\% of the general population. The prevalence of AF increases in the elderly $(6,7)$. In this study, patients with AF were statistically older. AF becomes a global health problem as the life expectancy of general population increases (8-11).

Stroke and AF have a complex interaction. In some cases, AF episodes with very short duration may be related to stroke. In some paroxysmal AF cases, stroke may occur long after the AF period. In some cases, atrial fibrillation may be triggered after a stroke. These various types of interactions between AF and stroke reveal that there is a more complex relationship than the traditional cardioembolic AF hypothesis. AF has strong associations with other cardiovascular diseases, such as heart failure, coronary artery disease (CAD), valvular heart disease, diabetes mellitus, and hypertension. Accompanying cardiac abnormalities may have potential effects on the onset of AF. In our study, AF patients with stroke had a significantly lower ejection fraction, decreased left ventricular function, increased left ventricular diameters, systolic dysfunction, mitral valve insufficiency, and tricuspid valve insufficiency. These findings are commonly associated with heart failure, coronary artery disease, and valvular heart diseases. It may be easily hypothesized that AF is only an independent risk factor for stroke. Our findings suggest that AF may be a consequence of multifactorial cardiac abnormalities that may have a causative effect for stroke (12-19).

\section{Study Limitations}

Limitations of the study are that the results of the echocardiographic findings were not assessed due to the retrospective pattern of the study and all patients were not evaluated by the same cardiologists.

\section{Conclusion}

AF patients with stroke had a significantly lower ejection fraction, decreased left ventricular function, increased left ventricular diameters, systolic dysfunction, mitral valve insufficiency, and tricuspid valve insufficiency. AF should not be considered as a major cardiac risk factor for stroke. AF may be a consequence of multifactorial cardiac abnormalities that may have a causative effect for stroke.

\section{Ethics}

Ethics Committee Approval: This retrospective observational study was approved by the institutional local ethics committee of Adıyaman University Hospital (2017/5-10).
Informed Consent: Retrospective study.

Peer-review: Externally peer-reviewed.

\section{Authorship Contributions}

Surgical and Medical Practices: M.Ö.E., Concept: A.A., Design: I.T., I.A., Data Collection or Processing: A.A., Analysis or Interpretation: M.Ö.E., Literature Search: A.A., S.Ç., H.A., M.A.A., Writing: A.A.

Conflict of Interest: No conflict of interest was declared by the authors.

Financial Disclosure: The authors declared that this study received no financial support.

\section{References}

1. Miyasaka Y, Barnes ME, Gersh BJ, Cha SS, Bailey KR, Abhayaratna WP, et al. Secular trends in incidence of atrial fibrillation in Olmsted County, Minnesota, 1980 to 2000, and implications on the projections for future prevalence. Circulation. 2006;114:119-25.

2. Chugh SS, Havmoeller R, Narayanan K, Singh D, Rienstra M, Benjamin EJ, et al. Worldwide epidemiology of atrial fibrillation: a Global Burden of Disease 2010 Study. Circulation. 2014;129:837-47.

3. Krijthe BP, Kunst A, Benjamin EJ, Lip GY, Franco OH, Hofman A, et al. Projections on the number of individuals with atrial fibrillation in the European Union, from 2000 to 2060. Eur Heart J. 2013;34:2746-51.

4. Go AS, Hylek EM, Phillips KA, Chang Y, Henault LE, Selby JV, et al. Prevalence of diagnosed atrial fibrillation in adults: national implications for rhythm management and stroke prevention: the AnTicoagulation and Risk Factors in Atrial Fibrillation (ATRIA) Study. JAMA. 2001;285:2370-75.

5. Ohlmeier C, Mikolajczyk R, Haverkamp W, Garbe E. Incidence, prevalence and antithrombotic management of atrial fibrillation in elderly Germans. Europace. 2013;15:1436-44.

6. Boriani G, Diemberger I, Martignani C, Biffi M, Branzi A. The epidemiological burden of atrial fibrillation: a challenge for clinicians and healthcare systems, Eur Heart J. 2006;27:893-4.

7. Camm AJ, Kirchhof P, Lip GY, Schotten U, Savelieva I, Ernst S, et al., Guidelines for the management of atrial fibrillation: the Task Force for the Management of Atrial Fibrillation of the European Society of Cardiology (ESC). Europace. 2010;12:1360-420.

8. Miyasaka Y, Barnes ME, Gersh BJ, Cha SS, Bailey KR, Abhayaratna WP, et al. Secular trends in incidence of atrial fibrillation in Olmsted County, Minnesota, 1980 to 2000, and implications on the projections for future prevalence. Circulation. 2006;114:119-25.

9. Boriani G, Maniadakis N, Auricchio A, Müller-Riemenschneider $F$, Fattore G, Leyva F, et al., Health technology assessment in interventional electrophysiology and device therapy: a position paper of the European Heart Rhythm Association. Eur Heart J. 2013;34:1869-74

10. Krijthe BP, Kunst A, Benjamin EJ, Lip GY, Franco OH, Hofman A, et al., Projections on the number of individuals with atrial fibrillation in the European Union, from 2000 to 2060. Eur Heart J. 2013;34:2746-51.

11. Boriani $G$. The epidemiologic threat of atrial fibrillation: need for secondary, primary, and primordial prevention, Chest. 2015;147:9-10.

12. Freestone B, Lip GY. The endothelium and atrial fibrillation, the prothrombotic state revisited. Hamostaseologie. 2008;4:207-12.

13. Watson T, Shantsila E, Lip GY. Mechanisms of thrombogenesis in atrial fibrillation: Virchow's triad revisited. Lancet. 2009;373:155-66. 
14. French Study of Aortic Plaques in Stroke Group, Amarenco P, Cohen A, Hommel M, Moulin T, Leys D, Bousser M-G. Atherosclerotic disease of the aortic arch as a risk factor for recurrent ischemic stroke. N Engl J Med. 1996:334:1216-21.

15. Benjamin EJ, Plehn JF, D'Agostino RB, Belanger AJ, Comai K, Fuller DL, et al., Mitral annular calcification and the risk of stroke in an elderly cohort. N Engl J Med. 1992;327:374-9.

16. Colak S, Erdogan MO, Afacan MA, Kosargelir M, Aktas S, Tayfur I, Kandis H. Neuropsychiatric side effects due to a transdermal fentanyl patch: hallucinations. American Journal of Emergency Medicine. 2015;33:477-e1.
17. Stein JH, Soble JS. Thrombus associated with mitral valve calcification: a possible mechanism for embolic stroke, Stroke. 1995;26:1697-9.

18. Sugioka K, Takagi M, Sakamoto S, Fujita S, Ito A, Iwata S et al., Predictors of silent brain infarction on magnetic resonance imaging in patients with nonvalvular atrial fibrillation: a transesophageal echocardiographic study. Am Heart J. 2015;169:783-90.

19. Ois A, Cuadrado-Godia E, Jiménez-Conde J, Gomis M, Rodríguez-Campello A, Martínez-Rodríguez JE, et al. Early arterial study in the prediction of mortality after acute ischemic stroke. Stroke. 2007;38:2085-9. 